\title{
Effect of Salt and Osmotic Stresses on the Germination of Pepper Seeds of Different Maturation Stages
}

\author{
Ibrahim Demir* and Kazım Mavi \\ Department of Horticulture; Faculty of Agriculture; University of Ankara; demir@agri.ankara.edu.tr;06110 \\ Ankara/Turkey
}

\begin{abstract}
Germination percentage, seedling fresh weight and sensitivity index of the pepper (Capsicum annuum L. cv. Sera Demre) seed lots harvested 50, 60 and 70 days after the anthesis (daa) in 2001 and 2002 were determined under the salt $(\mathrm{NaCl})$ and osmotic (PEG) stresses at the same water potentials of -0.3, -0.6 and -0.9 MPa. The objective was to study whether the germination and seedling growth were inhibited by the salt toxicity or osmotic effect during the development. The higher the salt and osmotic stress concentrations the lower was the germination percentage and seedling fresh weight. The seed germination was higher and sensitivity index were lower in NaCl than in PEG at the same water potential and harvest in both the years. They were able to germinate at all the concentrations of $\mathrm{NaCl}$ but at - $0.9 \mathrm{MPa}$ of PEG, none of the seeds of any harvest germinated in both the years. The seeds harvested 70 daa showed the highest germination and seedling weight in all the NaCl and PEG concentrations in both the years. Results showed that the inhibition of the germination at the same water potential of $\mathrm{NaCl}$ and PEG resulted from the osmotic effect rather than the salt toxicity. Moreover, the seeds harvested 70 daa appeared to be more tolerant to the salt and osmotic water stress conditions than the other two lots.
\end{abstract}

Key words: Capsicum annuum, salinity, water stress, germination

\section{INTRODUCTION}

The salinity stress is a major environmental constraint in the arid, semi-arid and coastal regions. Despite the salt resistance varies according to plant ontogeny, the first exposure of the crop to the salinity stress usually occur at the germination stage in direct sowing and transplanting production (Passam and Kakouriotis, 1994). The salt damage to the seed germination is attributed to various factors such as reduction in water availability, changes in mobilisation of stored reserves and affecting structural organisation of proteins (Foolad and Lin, 1997;
Almansouri et al., 2001; Machado Neto et al., 2004).

The seeds require higher amount of water uptake during the germination under the salt stress due to the accumulation of the soluble solutes around the seeds which increases the osmotic pressure. This causes excessive uptake of the ions which results in toxicity in the plant (Jones, 1986). Moreover, water potential gradient (reduced water availability) between the external environment and the seeds also inhibits the primary root emergence (Eneas Filho et al., 1995). More recently, MurilloAmador et al., (2002) found that salt $(\mathrm{NaCl})$ stress had lesser effect on the germination and seedling

\footnotetext{
${ }^{*}$ Author for correspondence
} 
growth of the cowpea seeds than did the water stress simulated by the PEG at the same osmotic potentials.

The seed lots, due to the once-over mechanical harvest in continuously flowering vegetables such as pepper are composed by the seeds of different maturation stages in the same lot. Determining the response of the seed lots at different maturation levels in terms of the germination performance under the saline and drought stress conditions would be useful to explain a possible relationship between the maturity and germination after exposure to a salt stress.

The experiments conducted here were undertaken to determine the germination percentage and seedling growth of the pepper seed lots harvested at three different maturation stages under the same osmotic potential of the salt $(\mathrm{NaCl})$ and water (PEG, Polyethlene Glyocol-6000) stresses. The objectives were to find out a) the effect of maturation stage on the germination under the salt and water stresses, b) germination and seedling growth were inhibited by the salt toxicity or osmotic effect.

\section{MATERIALS AND METHODS}

Pepper (Capsicum annuum L.) plants of the cultivar Sera Demre were grown in the open-field conditions in the years of 2001 and 2002. The maximum and minimum temperatures were recorded as 39 and $12^{\circ} \mathrm{C}$ during the growth season, respectively. The same plant cultivation practices were used as described in Demir (2002). Three hundred flowers were tagged each year at full anthesis and the fruits were harvested at 50,60 and 70 days after the anthesis (daa) in both the years. The seeds were extracted by hand and dried at 25 ${ }^{\circ} \mathrm{C}$ for $24 \mathrm{~h}$ to $10 \%$ moisture content. The germination, seedling fresh and dry weight determinations were conducted within one month after completion of the final harvest. The seed were stored in the sealed bags at $5{ }^{\circ} \mathrm{C}$ until the use. To determine the tolerance of the germination to the salt or the osmotic stress, the seeds were imbibed in the distilled water, solutions of Polyethylene Glycol (PEG-6000) or NaCl. The germination percentages were average of three replications of 50 seeds. The seeds of each replicate from each harvest and year, were placed on a Whatman paper (No: 42) moistened with 4.0 $\mathrm{ml}$ distilled water (control), $\mathrm{NaCl}$ or PEG-6000 solutions of $-0.3,-0.6$ and $-0.9 \mathrm{MPa}$ in $9.0 \mathrm{~cm}$ diameter Petri dishes and incubated at $25^{\circ} \mathrm{C}$ in the dark for 10 days. The solutions were prepared according to Coons et al., (1999) and estimated by Vapour Pressure Osmometer (Model 5520). Petri dishes were tightly sealed with the impermeable colourless film in order to avoid water losses during the incubation. Thiram was added to the solutions at a concentration of $0.2 \%(\mathrm{w} / \mathrm{v})$ to control the fungi infection. The germination was considered to have occurred when the primary root was $2 \mathrm{~mm}$ long.

The seedling fresh and dry weight were determined after $10^{\text {th }}$ day of germination test in all the germinated seedlings and expressed as $\mathrm{mg} / \mathrm{plant}$. The seedling dry weight was determined after drying at $80^{\circ} \mathrm{C}$ for $24 \mathrm{~h}$. For each harvest, the sensitivity of the germination was calculated as the ratio of the germination percentage under the salt and osmotic stress (-0.6 MPa) to that of under nonstress (control). The comparison was made by using only $-0.6 \mathrm{MPa}$ since germination percentages in some lots at -0.3 and $-0.9 \mathrm{MPa}$ were too high and low, respectively. This referred to as 'sensitivity index' is a measure of the relative sensitivity of a seed lot to the stress. Larger indices indicate higher sensitivity (Foolad and Lin, 1997). The germination and seedling fresh weight were analysed in three-way analyses using Anova. The percentages were angular transformed before analyses. Means were compared with LSD (Least significant difference, $\mathrm{P}=0.05$ ) values.

\section{RESULTS AND DISCUSSION}

Three way interaction (harvest, concentration and stress) in both the years were found significant $(\mathrm{P}<0.05,46 \mathrm{df})$. The maximum initial germination percentages at water were obtained in the seeds of 70 daa in both the years which was above $90 \%$. Corresponding values of the other lots were recorded as $80,87 \%$ at 60 daa, and $77,64 \%$ at 50 daa, in 2001 and 2002, respectively. The seed germination of all the harvests declined gradually as the concentration of $\mathrm{NaCl}$ and PEG were increased. However, difference between the germination at water (control) and that of -0.3 $\mathrm{MPa}$ was not $(\mathrm{P}>0.05)$ but was significant $(\mathrm{P}<0.05)$ at -0.6 and $0.9 \mathrm{MPa}$ in the salt and osmotic stresses. None of the seeds were able to germinate at $-0.9 \mathrm{MPa}$ of PEG. 
Table 1 - Changes in germination percentages of pepper seeds harvested 50, 60 and 70 daa at different osmotic potentials of $\mathrm{NaCl}$ and PEG. Values in the brackets are angular transformed percentages. Means were compared with $L S D$ values $(\mathrm{P}=0.05)$.

\begin{tabular}{|c|c|c|c|c|c|c|}
\hline \multirow[b]{3}{*}{$(\mathrm{MPa})$} & \multicolumn{5}{|c|}{2001 Harvest (daa) } & \\
\hline & \multicolumn{2}{|c|}{50} & \multicolumn{2}{|c|}{60} & \multicolumn{2}{|c|}{70} \\
\hline & $\mathrm{NaCl}$ & PEG & $\mathrm{NaCl}$ & PEG & $\mathrm{NaCl}$ & PEG \\
\hline 0 & $77 \quad(61.3)$ & $77 \quad(61.3)$ & $80 \quad(63.4)$ & $80 \quad(63.4)$ & $91 \quad(72.5)$ & $91 \quad(72.5)$ \\
\hline-0.3 & $59(50.3)$ & $60 \quad(50.7)$ & $76(60.6)$ & 77 (61.3) & $92(73.5)$ & $92 \quad(73.5)$ \\
\hline-0.6 & $56(48.4)$ & $25(30.0)$ & $69 \quad(56.1)$ & $38(38.0)$ & 89 (70.6) & $50 \quad(45.0)$ \\
\hline-0.9 & $24 \quad(29.3)$ & 0 & $56(48.4)$ & 0 & $64 \quad(53.1)$ & 0 \\
\hline
\end{tabular}

$\operatorname{LSD}(\mathrm{HxMxC}) \quad 11.43$

2002

\begin{tabular}{|c|c|c|c|c|c|c|}
\hline \multirow[b]{3}{*}{ (MPa) } & \multirow{2}{*}{\multicolumn{2}{|c|}{50}} & \multirow{2}{*}{\multicolumn{2}{|c|}{60}} & \multirow{2}{*}{\multicolumn{2}{|c|}{70}} \\
\hline & & & & & & \\
\hline & $\mathrm{NaCl}$ & PEG & $\mathrm{NaCl}$ & PEG & $\mathrm{NaCl}$ & PEG \\
\hline 0 & $64 \quad(53.1)$ & $64 \quad(53.1)$ & $87 \quad(68.8)$ & $87 \quad(68.8)$ & $92(73.5)$ & $92(73.5)$ \\
\hline-0.3 & $68 \quad(55.5)$ & $65 \quad(53.7)$ & $88 \quad(69.7)$ & $79(62.7)$ & $90 \quad(71.5)$ & 88 (69.7) \\
\hline-0.6 & $60 \quad(50.7)$ & $40 \quad(39.2)$ & 79 (62.7) & $59 \quad(50.3)$ & $90 \quad(71.5)$ & $69(56.1)$ \\
\hline-0.9 & $38 \quad(38.0)$ & 0 & $50 \quad(45.0)$ & 0 & $70 \quad(56.7)$ & 0 \\
\hline
\end{tabular}

LSD(HxMxC) 12.04, H: harvest, M: medium, C: Concentration

The seeds of 50, 60 and 70 daa germinated as 24, 56 and $64 \%$ in 2001, 38, 50 and $70 \%$ in 2002 at $0.9 \mathrm{MPa} \mathrm{NaCl}$ (Table 1).

Both the osmotic and toxic effects of the salts have been implicated in the inhibition of the germination (Allen et al., 1986, Machado Neto et al., 2004). Higher germination percentages obtained from $\mathrm{NaCl}$ compared to those of $\mathrm{PEG}$ at the same concentrations in the same harvest period proved that the adverse effect of PEG on the germination was due to an osmotic effect rather than specific ion accumulation. These results were consistent with Chartzoulakis and Klapaki (2000) in pepper and Murillo-Amador et al., (2002) in cowpea who affirmed that growth medium salinity or drought could affect the seed germination by decreasing the ease of uptake water. Mehra et al., (2003) proposed that the PEG molecules did not enter the seed and hence once water potential of the seed and around were in equilibrium the seed would not continue to imbibe.

Table 2 - Seedling fresh weigth of pepper seeds harvested 50, 60 and 70 daa in 2001 and 2002 and were germinated at different osmotic potentials of $\mathrm{NaCl}$ and PEG. Means were compared with LSD values $(\mathrm{P}=0.05)$.

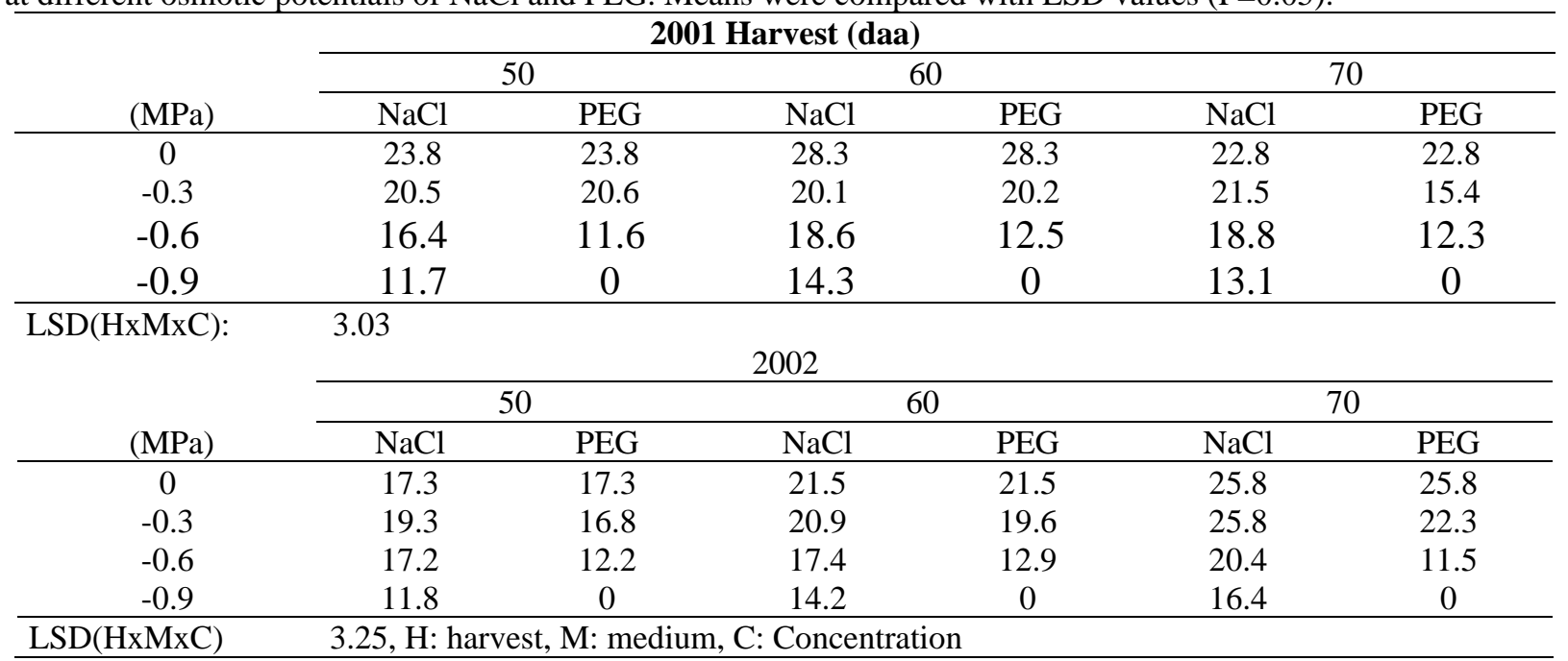

However, under the salt stress Na might be taken up by the seed, thus maintaining a water potential gradient so that the water uptake continued until the seed germinated. Contrarily, Bal and 
Chattopadhyay (1985) found in rice that the ion effect rather than osmotic effect was the main cause of delayed and retarded germination and seedling growth. This contrasting conclusions need to be approved by analyses of accumulation of the organic compatibles and ions in the seedlings in further work.

Although the suppression of growth and yield due to salinity has been reported in several species, its effect on the germination, particularly of differentially matured pepper lots is not known (Shannon and Grieve, 1999). Some of the earlier studies showed that the seeds harvested from the red-firm fruits of 70 daa attained the maximum seed quality traits assessed by the germination, emergence, seedling dry weight and storage longevity in the pepper (Demir and Ellis, 1992). Present results also indicated that the seeds harvested 70 daa had higher resistance to the stress conditions compared to earlier harvest. One reason might be the presence of higher reserved matter in the embryo (more developed embryo) in later harvests. Almansouri et al., (2001) reported that the salt tolerance was related to the mobilization of reserve material. The tolerance of the seed germination to the salinity was a measure of the seed ability to withstand the effects of high concentration of soluble salts in the medium. It seemed that the seeds harvested 70 daa were capable to generate required osmotic potential to improve the water status of the embryo, permitting protrusion of the primary root better than earlier ones (Hegarty, 1978). Agreeing with these conclusions, Still and Bradford (1998) in cabbage and rape seeds, Welbaum and Bradford (1990) in muskmelon, Demir et al., (2003) in aubergine seeds also found that the immature seeds were more sensitive to the externally applied osmotic potential and salt stresses than that of mature.

Table 3 - Seedling dry weigth of pepper seeds harvested 50, 60 and 70 daa in 2001 and 2002 and were germinated at osmotic potentials of $\mathrm{NaCl}$ and PEG. Means were compared with LSD values $(\mathrm{P}=0.05)$.

\begin{tabular}{cccccccc}
\hline & \multicolumn{9}{c}{ 2001 Harvest (daa) } & & & & \\
\cline { 2 - 8 }$(\mathrm{Mpa})$ & $\mathrm{NaCl}$ & $\mathrm{PEG}$ & $\mathrm{NaCl}$ & $\mathrm{PEG}$ & $\mathrm{NaCl}$ & $\mathrm{PEG}$ \\
\cline { 2 - 8 } & 3.5 & 3.5 & 3.3 & 3.3 & 3.1 & 3.1 \\
-0.3 & 3.9 & 5.4 & 3.3 & 5.7 & 3.3 & 5.1 \\
-0.6 & 4.7 & 6.1 & 5.5 & 6.0 & 4.9 & 6.0 \\
-0.9 & 5.5 & 0 & 4.9 & 0 & 5.1 & 0 \\
\hline
\end{tabular}

$\operatorname{LSD}(\mathrm{HxMxC})$

1.3

\begin{tabular}{|c|c|c|c|c|c|c|}
\hline \multirow[b]{3}{*}{ (Mpa) } & \multirow{2}{*}{\multicolumn{4}{|c|}{2002}} & \multirow{2}{*}{\multicolumn{2}{|c|}{70}} \\
\hline & & & & & & \\
\hline & $\mathrm{NaCl}$ & PEG & $\mathrm{NaCl}$ & PEG & $\mathrm{NaCl}$ & PEG \\
\hline 0 & 2.1 & 2.1 & 2.2 & 2.2 & 2.3 & 2.3 \\
\hline-0.3 & 2.6 & 4.0 & 2.8 & 5.0 & 3.5 & 4.7 \\
\hline-0.6 & 3.6 & 5.6 & 3.9 & 5.1 & 4.3 & 5.7 \\
\hline-0.9 & 4.0 & 0 & 4.5 & 0 & 5.2 & 0 \\
\hline
\end{tabular}

LSD(HxMxC) 1.1 , H: harvest, M: medium, C: Concentration

The seeds that grew at $\mathrm{NaCl}$ concentrations had higher seedling fresh weight but lower dry weight than that of PEG in all the harvests (Table 2 and 3). Higher seedling fresh weight values were obtained at $\mathrm{NaCl}$ than the osmotic stress at -0.6 and $-0.9 \mathrm{MPa}$ in all the harvests. In contrast to significant decrease in the fresh weight, the seedling dry weight increased as the stress concentrations increased. This indicated that the higher seedling fresh weight at control was mainly due to an increase in the tissue water content. More recently, Foolad and Lin (1997) examined the tomato seed germination in different ionic and nonionic germination media with identical osmotic potential. They concluded that the tomato seed germination rate was mainly affected by the osmotic rather than ionic effects of the medium. It could be concluded that the stress imposition resulted in higher gains in the biomass which could be attributed to the increased cell division and material synthesis such as sugars (Gill et al., 2003). In turn, the increase in the level of the biomass (i. e. sugars) in the tissues could also help in effective osmoregulation under the stress conditions (Spyropoulos, 1982). 
The seedling growth, dry weight and emergence in the carrot (Schmidhalter and Oertli, 1991), cucumber (Passam and Kakouriotis, 1994) and aubergine (Demir et al., 2003) have been reported to be more sensitive to the salinity comparing to the seed germination. The salt and osmotic stress inhibited to the seed germination as well as the seedling weight in this work. Therefore, the sensitivity to the stress manifests itself both through the germination and seed vigour (seedling weight) in this experiment. It appeared that the imposed stress conditions restricted the water to reach the threshold level for the germination and subsequently retarded the seedling growth (Hegarty, 1978).

Table 4 Sensitivity index values of pepper seed lots at $-0.6 \mathrm{MPa}$ of $\mathrm{NaCl}$ and PEG solution

\begin{tabular}{|c|c|c|c|c|c|c|}
\hline \multirow[b]{3}{*}{ Year } & \multicolumn{4}{|c|}{ Harvest (daa) } & \multirow{2}{*}{\multicolumn{2}{|c|}{70}} \\
\hline & \multicolumn{2}{|c|}{50} & \multicolumn{2}{|c|}{60} & & \\
\hline & $\mathrm{NaCl}$ & PEG & $\mathrm{NaCl}$ & PEG & $\mathrm{NaCl}$ & PEG \\
\hline 2001 & 1.4 & 3.0 & 1.2 & 2.1 & 1.0 & 1.8 \\
\hline 2002 & 1.1 & 1.6 & 1.1 & 1.5 & 1.0 & 1.3 \\
\hline
\end{tabular}

The sensitivity index (Foolad and Lin, 1997) indicated that the seeds of all the harvests were more sensitive to the osmotic stress than that of $\mathrm{NaCl}$. Among the harvests, the least sensitive lot to the salt and osmotic stress was 70 daa in both the years (Table 4). Concerning the determination of the right time of the seed harvest to get the maximum germination efficiency and stand establishment in the saline and water deficit soils, the pepper seeds should be harvested at 70 daa.

\section{ACKNOWLEDGMENTS}

We express sincere thanks for the Directorate of scientific research projects of Ankara University for the financial support

\section{REFERENCES}

Allen, S. G., Dobrenz, A. K., Bartels, P. G. (1986), Physiological response of salt-tolerance and nontolerant alfalfa to salinity during germination. Crop Science, 26, 1004-1008.

Almansouri, M., Kinet, M., Lutts, S. (2001), Effect of salt and osmotic stresses on germination in durum wheat (Triticum durum Desf.). Plant and Soil, 231, 243-254.

Bal, A. R., Chattopadyay, N. C. (1985), Effects of $\mathrm{NaCl}$ and PEG-6000 on germination and seedling growth of rice (Oryza sativa L.). Biol. Plant., 27, 65-69.
Chartzoulakis, K., Klapaki, G. (2000), Response of two different greenhouse pepper hybrids to $\mathrm{NaCl}$ salinity during different growth stages. Sci. Hortic., 86, 247260.

Coons, M. J., Kuehl, R. O., Simons, N. R. (1990), Tolerance of ten lettuce cultivars to high temperature combined with NaCI during germination. J. Amer. Soc. Hort. Sci., 115 (6), 1004-1007.

Demir, I., Ellis, R H. (1992), Changes in seed quality during seed development and maturation in pepper. Ann. App. Biol., 121, 385-399.

Demir, I. (2002), The effect of controlled hydration treatment on germination and seedling emergence of unaged and aged pepper seeds during development. Israel J. Plant Sci., 50, 251-257.

Demir, I., Mavi, K., Ozcoban, M., Okcu, G. (2003), Effect of salt stress on germination and seedling growth in serially harvested aubergine (Solanum melongena L.) seeds during development. Israel J. Plant Sci., 51, 125-131.

Eneas, Filho, J., Oliveira Neto. O. B., Prisco, J. T., Gomes Filho, E., Monteiro C. (1995), Effects of salinity in vivo and in vitro on cotyledonary galactosidases from Vigna unguiculata (L.) Walp. during seed germination and seedling stablishment. Revista Brasileira de Fisiologia Vegetal, 7 (2), 135142.

Foolad, M. R., Lin, G. Y. (1997) Genetic potential for salt tolerance during germination in Lycopersicon species. Hortscience, 32, 296-300.

Gill, P. K., Sharma, A. D., Singh, P., Bhullar, S. S. (2003), Changes in germination growth and soluble sugar contents of Sorghum bicolor (L.) Moench seeds under various abiotic stresses. Plant Growth Regulation, 40, 157-162. 
Hegarty, T W. (1978), The physiology of seed hydration and dehydration and relation between water stress and control of germination: a review. Plant Cell and Environment, 1, 1001-1119.

Jones, R. A. (1986), High salt tolerance potential in Lycopersicon species during germination. Euphytica, 35, 575-582.

Machado Neto, N. B., Saturnino S. M., Bomfim, D. C. and Custodio, C. C. (2004), Water stress induced by Mannitol and Sodium chloride in Soybean cultivars. Brazilian Archieves of Biology and Technology. 47 (4), 521-529.

Mehra, V., Tripathi, J., Powell, A. A. (2003), Aerated hydration treatment improves the response of Brassica juncea and Barassica campestris seeds to stress during germination. Seed Sci. Technol., 31, 5770.

Murillo-Amador, B., Lopez-Aguilar, R., Kaya, C., Larrinaga-Mayoral, J., Flores-Hernandez, A. (2002), Comparative effect of $\mathrm{NaCl}$ and $\mathrm{PEG}$ on germination emergence and seedling growth of cowpea. J. Agron. Crop Sci., 188, 235-247.

Passam, H. C., Kakouriotis, D. (1994), The effects of osmoconditioning on the germination emergence and early plant growth of cucumber under saline conditions. Sci. Hortic., 57, 233-240.
Schmidhalter, U., Oertli, J. J. (1991), Germination and seedling growth of carrots under salinity and moisture stress. Plant and Soil, 132, 243-251.

Shannon, M. C., Grieve, C. M. (1999), Tolerance of vegetable crops to salinity. Sci. Hortic., 78, 5-38.

Still, D. W., Bradford, K. J. (1998), Using hydrotime and ABA-times model to quantify seed quality of Brassicas during development. J. Amer. Soc. Hort. Sci., 123(4), 692-699.

Spyroupoulos, C. G. (1982), Control of sucrose metabolism in polyethylene glycol stressed carob young seedling: The role of sucrose. J. Exp. Bot. 33, 1210-1219.

Welbaum, G. E., Tissaoui, T., Bradford, K. J. (1990), Water relations of seed development and germination in muskmelon (Cucumis melo L.). III. Sensitivity of germination to water potential and abscisic acid during development. Plant Physiology, 92, 10291037.

Received: November 01, 2005; Revised: May 25, 2007; Accepted: February 11, 2008. 